\title{
A Probabilistic Tropical Cyclone Track Forecast Scheme Based on the Selective Consensus of Ensemble Prediction Systems
}

\author{
XIPING ZHANG AND HUI YU \\ Shanghai Typhoon Institute, China Meteorological Administration, Shanghai, China
}

(Manuscript received 1 June 2017, in final form 12 October 2017)

\begin{abstract}
Selective consensus and a grand ensemble based on an ensemble prediction system (EPS) have been found to be effective in improving deterministic tropical cyclone (TC) track forecasts, while little attention has been paid to quantitative applications of the forecast uncertainty information provided by EPSs. In this paper the forecast uncertainty information is evaluated for two operational EPSs and their grand ensemble. Then, a probabilistic TC track forecast scheme is proposed based on the selective consensus of the two EPSs; this scheme is composed of member picking, mean track shifting, and probability ellipses. The operational EPSs are from the European Centre for Medium-Range Weather Forecasts (ECMWF-EPS) and the National Centers for Environmental Prediction (NCEP-GEFS). Evaluation exhibits that the hit ratios of ECMWFEPS are above $80 \%$ for the $70 \%$ probability ellipses at all lead times until $120 \mathrm{~h}$ and are used in the proposed scheme. The other components of the proposed scheme are about picking potentially good EPS members. A picking ratio of $1 / 2$ is found to be the best choice, and the member-picking technique is used for the grand ensemble but only for lead times out to $48 \mathrm{~h}$. For lead times longer than $48 \mathrm{~h}$, all of the grand ensemble members are used in obtaining the mean track. The effectiveness of the proposed scheme shows a $10 \%$ improvement in the mean track forecast errors over the grand ensemble and a $4.5 \%$ improvement in the hit ratio of $70 \%$ probability ellipses over the ECMWF-EPS at $24 \mathrm{~h}$, demonstrating its good potential to be applied in operations.
\end{abstract}

\section{Introduction}

Motion is a fundamental aspect of tropical cyclone (TC) forecasting (Wang 2014; Majumdar and Finocchio 2010). Improved track forecasting has been shown to improve other aspects of TC forecasting such as wind speed, storm surge, and precipitation. Additionally, more accurate track forecasting can reduce unnecessary warnings and evacuations, and lead to more efficient emergency management decision-making (Hamill et al. 2012).

Because of the remarkable progress in computational power and numerical weather prediction (NWP) models, track forecasts of TCs have been improved significantly during the past few decades. Additionally, the use of a multimodel consensus in operational centers became widespread about 15 years ago in an effort to improve track forecasts, which usually outperforms the individual models (Krishnamurti et al. 2010; Sampson et al. 2005; Goerss et al. 2004). There are two main methods for

\footnotetext{
Corresponding author address: Xiping Zhang, zhangxp@typhoon. org.cn
}

creating a consensus. The first is to take a simple average of all participating models, and the second is to take a weighted average of them, with the weights usually estimated from the error statistics of participating models in previous years (Krishnamurti et al. 2000; Hamill et al. 2012). The main limitation of the second method is that the relevance between the present and past forecasts is weakened if there are major changes in the models.

The atmosphere is a complicated nonlinear dynamic system (Pedlosky 1987). For numerical weather forecast models, forecast uncertainties are inevitably caused by the chaotic growth of initial condition errors and model imperfections (Lorenz 1995; Zhang and Zhao 2016). As a result, the atmosphere cannot be completely described with a single deterministic forecast as a result of these inherent uncertainties. The prediction of forecast uncertainty is therefore necessary. Multimodel consensus methods produce a more skillful deterministic forecast, but they still do not provide an adequate measure of the uncertainty associated with the forecast. In ensemble prediction systems (EPSs), the two major sources of uncertainty, the initial conditions and the model error, are 
estimated by conducting multiple simulations. Slightly different initial conditions are used to account for imperfect observations or reanalysis, and the stochastic dynamics and different parameterizations or models are used for the model imperfections. Thus, compared with a deterministic prediction, EPSs can quantify the forecast uncertainty, which could be expressed in the form of possible state and probability distributions (Goerss 2007; Majumdar and Finocchio 2010; Zhang and Zhi 2015; Zhi et al. 2012), thus facilitating informed decision-making by providing case-dependent uncertainty estimates.

Besides providing the uncertainty information, the simple mean of single and multi-EPSs are prepared by many NWP centers and are often used in track forecasting as a consensus member. Some EPS mean tracks may outperform the best deterministic NWP model (Qi et al. 2014; He et al. 2015), and certain multicenter grand ensembles usually perform better than the single-model ensemble from both deterministic and probabilistic perspectives (Yamaguchi et al. 2012). However, those multi-EPS applications are still based mainly on ideas of deterministic prediction ( $\mathrm{Du}$ et al. 2016; Yamaguchi et al. 2012; He et al. 2015; H. B. Zhang et al. 2015; Weigel et al. 2008) like the multimodel consensus.

To compose a consensus, both the selection of the EPS and the ensemble members within each EPS are important. Besides selections based on historical runs, short lead time errors and ensemble spread information are also used to select ensemble members. By making use of the latest observations and errors at short lead times, Qi et al. (2014) applied means and weighted means to selected ensemble members and found improvements in four different EPSs over a simple ensemble mean. Qian et al. (2014) proposed a similar real-time technique of TC track correction for the EPS from ECMWF and studied the influence of position errors. They both did their research under the premise that errors at short and following lead times are related; however this premise has been left unproven. In other studies (He et al. 2015; H. B. Zhang et al. 2015), a Kalman filter and a bias-removed ensemble mean were employed to conduct TC forecast consensus experiments in a deterministic way while only the ensemble mean of each EPS was used. Additionally, the probabilistic products in operation are mostly statistically based and usually in the form of a probability circle (Dupont et al. 2011). For example, at the Japan Meteorological Agency (JMA) the radii of $70 \%$ probability circles within $96 \mathrm{~h}$ are determined statistically depending on the movement, direction, and speed of a TC (Kunitsugu 2012; Yamaguchi et al. 2009). More attention should be paid to drawing situation-dependent uncertainty information from the EPS results (Hamill et al. 2012; X. P. Zhang et al. 2015).
TABLE 1. Specifications of ECMWF-EPS and NCEP-GEFS for 2014-15.

\begin{tabular}{lcc}
\hline \hline \multicolumn{1}{c}{ Model name } & ECMWF-EPS & NCEP-GEFS \\
\hline Model resolution & TL639 & T254L42 \\
Ensemble size & 51 & 21 \\
Prediction time (UTC) & 0000,1200 & $0000,0600,1200,1800$ \\
Lead time interval (h) & 6 & 6 \\
\hline
\end{tabular}

X. P. Zhang et al. (2015) found that the levels of performance of EPSs from different operational centers differ, and track forecasts from the ECMWF and the National Centers for Environmental Prediction (NCEP) perform much better than those from other sources. In this paper the ensemble track forecasts from ECMWF and NCEP are used to study track corrections in both deterministic and probabilistic ways. We focus mainly on the study of possible techniques for track improvements and, finally, produce an optimal scheme after the verification of those techniques. This article is organized as follows. In section 2 the two EPSs and datasets used in our study are introduced. In section 3 the overall analysis of the two EPSs and their grand ensemble are given. Then, three techniques designed to generate track improvements are discussed in the following two sections. The member-picking methods for different lead times are studied in section 4 , and the effects of horizontal shifting are studied in section 5. Finally, the new scheme is detailed in section 6. Our conclusions can be found in section 7 .

\section{Datasets and methodology}

\section{a. Datasets}

The data used in this study are ensemble track forecasts from ECMWF and NCEP (hereinafter ECMWFEPS and NCEP-GEFS) from 2014 to 2015 over the western North Pacific and South China Sea. During this time, 50 tropical cyclones reached tropical storm intensity or higher. The TC track forecasts of the two EPSs are decoded from the North Western Pacific Tropical Cyclone Ensemble Forecast Project of THORPEX Interactive Grand Global Ensemble (TIGGE; WMO 2015), and archived through the WMO's Typhoon Landfall Forecast Demonstration Project (Lei and Yu 2015). Details about the two EPSs can be found in Table 1. ECMWF-EPS predicts twice per day, while NCEPGEFS predicts four times per day. Since all the comparisons are performed with the same samples in this paper, only forecasts at 0000 and 1200 UTC are used for NCEP-GEFS.

The discrepancies among major best-track datasets are negligibly small in TC center positions, and the main difference lies in intensity (Song et al. 2010). In 
TABLE 2. Mean track error for different EPSs $(\mathrm{km}) ; I_{\mathrm{EC}}$ denotes the improvement in EPS-CON compared to ECMWF-EPS, and $I_{\mathrm{NCEP}}$ denotes that compared to NCEP-GEFS. The numbers in parentheses are the sample sizes for each prediction time.

\begin{tabular}{|c|c|c|c|c|c|c|c|c|c|c|}
\hline & $12 \mathrm{~h}$ & $24 \mathrm{~h}$ & $36 \mathrm{~h}$ & $48 \mathrm{~h}$ & $60 \mathrm{~h}$ & $72 \mathrm{~h}$ & $84 \mathrm{~h}$ & $96 \mathrm{~h}$ & $108 \mathrm{~h}$ & $120 \mathrm{~h}$ \\
\hline EPS & $(486)$ & $(465)$ & (439) & (410) & (381) & (353) & $(325)$ & (295) & (265) & (239) \\
\hline ECMWF-EPS & 44.8 & 64.2 & 85.5 & 111.0 & 137.9 & 164.6 & 190.7 & 228.1 & 274.8 & 324.9 \\
\hline NCEP-GEFS & 44.4 & 66.1 & 91.1 & 119.8 & 153.3 & 192.8 & 231.6 & 276.9 & 324.4 & 391.8 \\
\hline EPS-CON & 39.0 & 57.8 & 78.4 & 102.3 & 128.3 & 155.0 & 181.3 & 214.0 & 254.6 & 306.2 \\
\hline$I_{\mathrm{EC}}(\%)$ & 12.9 & 10.0 & 8.3 & 7.8 & 7.0 & 5.8 & 4.9 & 6.2 & 7.4 & 5.8 \\
\hline$I_{\text {NCEP }}(\%)$ & 12.2 & 12.6 & 13.9 & 14.6 & 16.3 & 19.6 & 21.7 & 22.7 & 21.5 & 21.8 \\
\hline
\end{tabular}

our paper only the TC center positions are adopted, so the validity of the proposed scheme will not be affected by the choice of the best-track datasets. The best-track data used are obtained from the Shanghai Typhoon Institute of the China Meteorological Administration (CMA) best-track dataset for TCs over the western North Pacific (http://www.typhoon.org. cn/; Ying et al. 2014).

\section{b. The probability ellipse}

We use ellipses to indicate the concentration area of scatter dots in this paper. Here, a short introduction into the calculations is given.

Suppose that a two-dimensional random variable $(X, Y)$ has bivariate normal distribution; its probability density function will be

$$
f(x, y)=\frac{1}{2 \pi a b} \exp \left[-\frac{1}{2}\left(\frac{x^{2}}{a^{2}}+\frac{y^{2}}{b^{2}}\right)\right]
$$

(Xu and Lu 2004). The values of $a$ and $b$ are calculated by the first and second modes obtained from an empirical orthogonal function (EOF) decomposition of the samples, thus reflecting the sample spatial distribution. To be more specific, the first mode defines the principal axis along which the projection has the most variance; $a$ is along this first principal component and equals the square root of the corresponding variance. Similarly, $b$ is along the second mode and equals the square root of the second variance.

The probability of $(X, Y)$ appearing in the ellipse defined by $a$ and $b$,

$$
\frac{x^{2}}{a^{2}}+\frac{y^{2}}{b^{2}}=\sigma^{2}
$$

is

$$
P\left\{\frac{X^{2}}{a^{2}}+\frac{Y^{2}}{b^{2}} \leq \sigma^{2}\right\}=1-e^{-\sigma^{2} / 2},
$$

where $e$ is the base of the natural logarithm, and $\sigma$ is determined by the chosen proportion.
Thus, we can estimate an ellipse, determined by $a, b$, and $\sigma$, for the bivariate normal distribution, into which a sample $(X, Y)$ falls with a specific probability, say $70 \%$ or $20 \%$.

In other words, the ellipse is used to identify the concentration area of data, which is determined by the statistical characteristics of all samples regardless of the proportion. In section $3 b$, the ellipse indicates the concentration area of forecast cases, and the probability ellipse in section $3 \mathrm{c}$ shows the concentration areas of ensemble members for a particular case.

\section{Overall evaluation of EPS means and spreads}

\section{a. Ensemble means}

Table 2 shows the mean track errors for ECMWF-EPS, NCEP-GEFS, and their grand ensemble (hereinafter EPS-CON) using the same samples. Here, the numbers in parentheses are the sample sizes of each column, which are the same for other tables. As for the bottom two rows, $I_{\mathrm{EC}}$ denotes the improvement of EPS-CON compared to ECMWF-EPS, and $I_{\mathrm{NCEP}}$ denotes that compared to NCEP-GEFS.

It is shown that EPS-CON outperforms the other two at each prediction time; for example, the errors are reduced by about $86 \mathrm{~km}(21.8 \%)$ and $19 \mathrm{~km}(5.8 \%)$ compared to those of NCEP-GEFS and ECMWF-EPS at $120 \mathrm{~h}$, respectively. To be more specific, the improvement of EPS-CON over NCEP-GEFS is larger than $10 \%$ throughout and larger than $20 \%$ after $72 \mathrm{~h}$. The improvement over ECMWF-EPS is smaller, and it is less than $8 \%$ after $36 \mathrm{~h}$. In general, the performance of ECMWF-EPS is better than that of NCEP-GEFS except for a prediction time of $12 \mathrm{~h}$, when the results are very similar.

Yamaguchi et al. (2012) examined the ensemble TC track predictions from nine centers during 2008-10 and found that the consensus of the "superensemble" performed better than the best of the nine, namely ECMWF-EPS. X. P. Zhang et al. (2015) evaluated the track forecasts of five ensemble prediction systems in 2014 and found that the mean track errors of ECMWFEPS and NCEP-GEFS are in different directions, to 


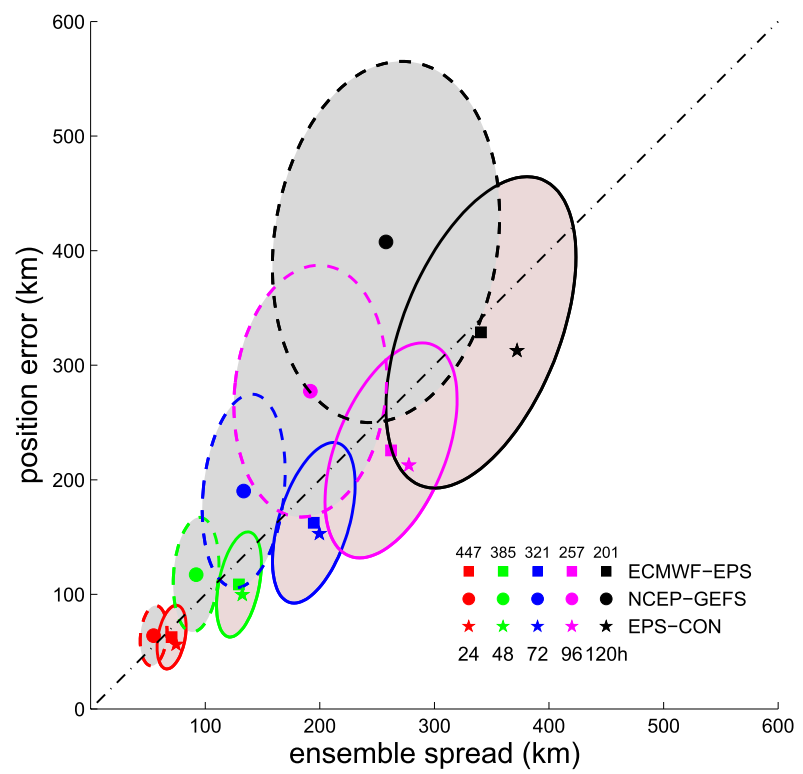

FIG. 1. The ensemble spread and position error. The ellipse contains about $20 \%$ of the samples at each prediction time. The dashed ellipses are for NCEP-GEFS, and solid ones are for ECMWF-EPS. The square, circle, and star are the mean values for ECMWF-EPS, NCEP-GEFS, and EPS-CON, respectively. The sample sizes (prediction times) are labeled in the first (last) line of the legend.

some extent. This means that the position errors of the ECMWF-EPS and NCEP-GEFS members may cancel each other in the superensemble, leading to improvements in the track forecasts. In this section it is shown that the grand ensemble of these two can bring down the track error; thus, the consensus EPS-CON mean is a better choice than the individual means, which is consistent with previous findings of Yamaguchi et al. (2012) and Du et al. (2016).

\section{b. Ensemble spread}

Ensemble spread (SPRD) is an indicator of forecast uncertainty, which is measured by the root-mean-square error of distances between ensemble members and the ensemble mean (Whitaker and Loughe 1998):

$$
\mathrm{SPRD}=\sqrt{\frac{1}{N} \sum_{n=1}^{N}[\bar{f}-f(n)]^{2}},
$$

where $N$ is the ensemble size, $\bar{f}=(1 / N) \sum_{n=1}^{N} f(n)$ is the ensemble mean, and $f(n)$ is the forecast value of member $n$.

The position error of the ensemble mean is Perror $=|\bar{f}-r|$, where $r$ is the best-track value. EPSs are supposed to provide the case-dependent uncertainty estimates. For an ideal EPS, SPRD and Perror should be the same size (Jolliffe and Stephenson

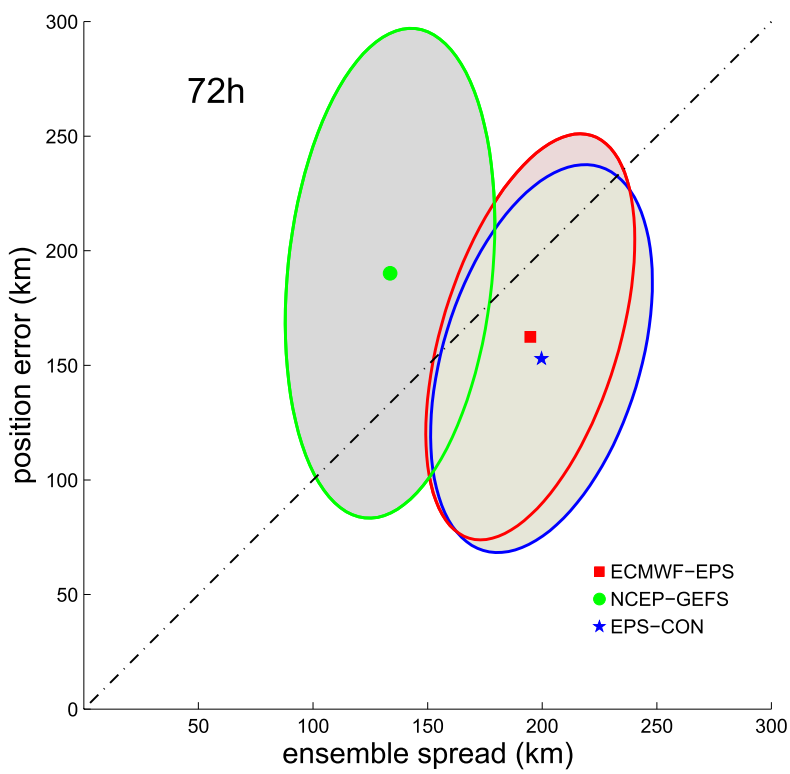

FIG. 2. The ensemble spread and position error for the prediction time of $72 \mathrm{~h}$. The notations are the same as in Fig. 1.

2003). If SPRD $>$ Perror, the system spread is larger, and atmospheric uncertainties are overestimated. If SPRD $<$ Perror, the atmospheric uncertainties are underestimated, and the ensemble spread is therefore too small. Note that we have excluded forecasts that contained less than $2 / 3$ of the ensemble size for any given EPS when calculating the spread and probability ellipse.

The relationship between SPRD and Perror in the studied time range is shown in Fig. 1. To make the results more readable, we only draw the $20 \%$ ellipses, which indicate the concentration area of forecast cases and contain about $20 \%$ of them, and only plot the respective ellipses for ECMWF-EPS and NCEP-GEFS. Compared with NCEP-GEFS, the samples of ECMWF-EPS are more concentrated and closer to the diagonal line, and with larger areas under the diagonal line, this implies that ECMWF-EPS tends to overestimate the atmospheric uncertainties. As for NCEP-GEFS, it tends to underestimate the atmospheric uncertainties as more samples are found above the diagonal line. The stars denote their grand ensemble, and it is shown that the mean position errors decrease despite the increase in the ensemble spreads. The increase may be caused by having the concentration area of NCEP-GEFS forecasts away from that of the ECMWFEPS forecasts, and the decrease in mean position errors illustrates that the forecast errors of the two have canceled each other to some extent. In Fig. 2 only the case for a prediction time of $72 \mathrm{~h}$ is plotted, and we can see clearly that the consensus represents a slight adjustment to ECMWF-EPS in the mean position error. Note that the 
TABLE 3. The hit ratio (first line of each row; \%) and the mean major-minor axes (second line of each row; ${ }^{\circ}$ ) of the $70 \%$ probability ellipse. The numbers in parentheses are as in Table 2.

\begin{tabular}{|c|c|c|c|c|c|c|c|c|c|c|}
\hline & $12 \mathrm{~h}$ & $24 \mathrm{~h}$ & $36 \mathrm{~h}$ & $48 \mathrm{~h}$ & $60 \mathrm{~h}$ & $72 \mathrm{~h}$ & $84 \mathrm{~h}$ & $96 \mathrm{~h}$ & $108 \mathrm{~h}$ & $120 \mathrm{~h}$ \\
\hline EPS & $(469)$ & $(447)$ & (417) & $(385)$ & (354) & (321) & $(290)$ & (257) & $(231)$ & (201) \\
\hline \multirow[t]{2}{*}{ ECMWF-EPS } & 84.9 & 86.1 & 87.8 & 89.1 & 92.7 & 92.5 & 90.0 & 89.9 & 89.2 & 87.1 \\
\hline & $0.55-0.38$ & $0.87-0.57$ & $1.23-0.77$ & $1.65-0.97$ & 2.09-1.17 & $2.55-1.36$ & $3.01-1.54$ & $3.52-1.72$ & $4.08-1.93$ & $4.64-2.18$ \\
\hline \multirow[t]{2}{*}{ NCEP-GEFS } & 64.0 & 68.7 & 67.1 & 65.5 & 59.0 & $51.1 \%$ & 44.8 & 44.4 & 42.0 & 41.8 \\
\hline & $0.44-0.25$ & $0.71-0.41$ & $0.95-0.53$ & $1.23-0.63$ & $1.51-0.73$ & $1.84-0.84$ & $2.23-0.94$ & $2.72-1.07$ & $3.18-1.24$ & $3.72-1.44$ \\
\hline \multirow[t]{2}{*}{ EPS-CON } & 93.8 & 93.7 & 92.1 & 93.8 & 94.9 & 93.8 & 94.5 & 92.6 & 90.9 & 89.6 \\
\hline & $0.60-0.40$ & $0.92-0.59$ & $1.28-0.78$ & $1.69-0.97$ & $2.14-1.16$ & $2.63-1.35$ & $3.14-1.55$ & $3.76-1.73$ & $4.44-1.95$ & $5.13-2.23$ \\
\hline
\end{tabular}

stars, which are the sample means of EPS-CON, still deviate from the idealized diagonal in the spread-error relationship.

The means of the samples discussed above show only their statistical characteristics or tendencies. For example, ECMWF-EPS tends to overestimate the atmospheric uncertainties; however, there are still many underestimated cases, as shown by those above the diagonal line. In addition, ensemble spread as a level of confidence of the prediction is not necessarily in a linear relationship with mean track error (Yamaguchi et al. 2012). When the ensemble spread is large, the position error may be small and vice versa (see Figs. 1 and 2).

\section{c. Hit ratio}

The uncertainty information provided by the spread of the EPS can be expressed in the form of probability circles or ellipses, whose sizes can be optimized by the probability distribution of forecast positions. Based on ensemble spread, Hamill et al. $(2011,2012)$ and X. P. Zhang et al. (2015) derive the situation-dependent probability ellipse, containing uncertainty information about moving speed and moving direction, as well as position uncertainties. In this section the uncertainty is dealt with quantitatively by evaluating the probability ellipse, and the ellipse here indicates the concentration area of the ensemble members. The typical value of $70 \%$ used by many operational forecasting centers ( $\mathrm{Yu}$ et al. 2012) is chosen here. Hit ratio and major-minor axes are adopted to evaluate the ellipse in detail. Hit ratio is defined as the ratio of TCs falling into the corresponding ellipse throughout the verification time range, and the major-minor axes are the same as the standard mathematical definitions. A detailed introduction to the probability ellipse can be found in section 2b and Hamill et al. (2011, 2012).
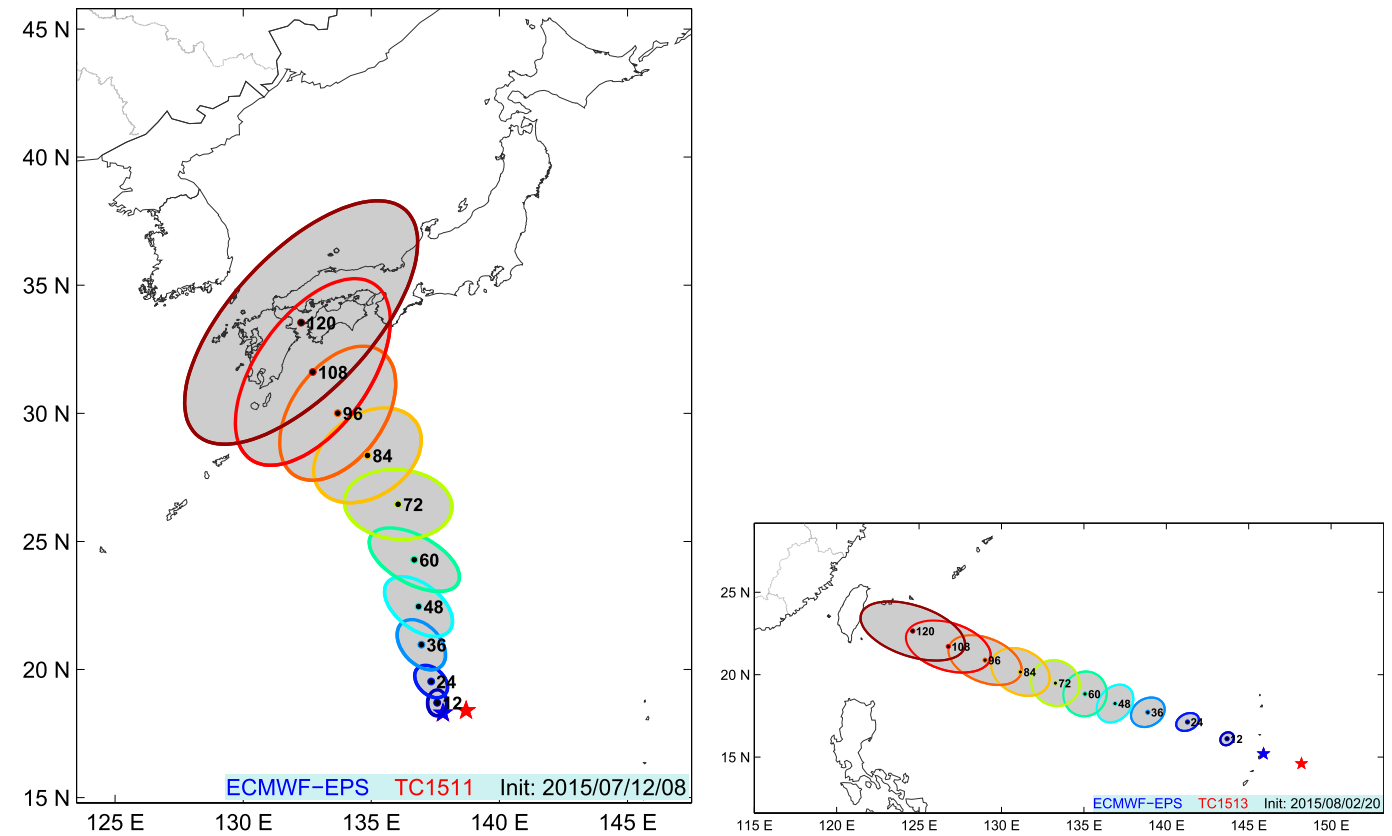

FIG. 3. Two example diagrams of the $70 \%$ probability ellipse. The stars depict the best track, and the colored ellipses are probability ellipses for different prediction times. 

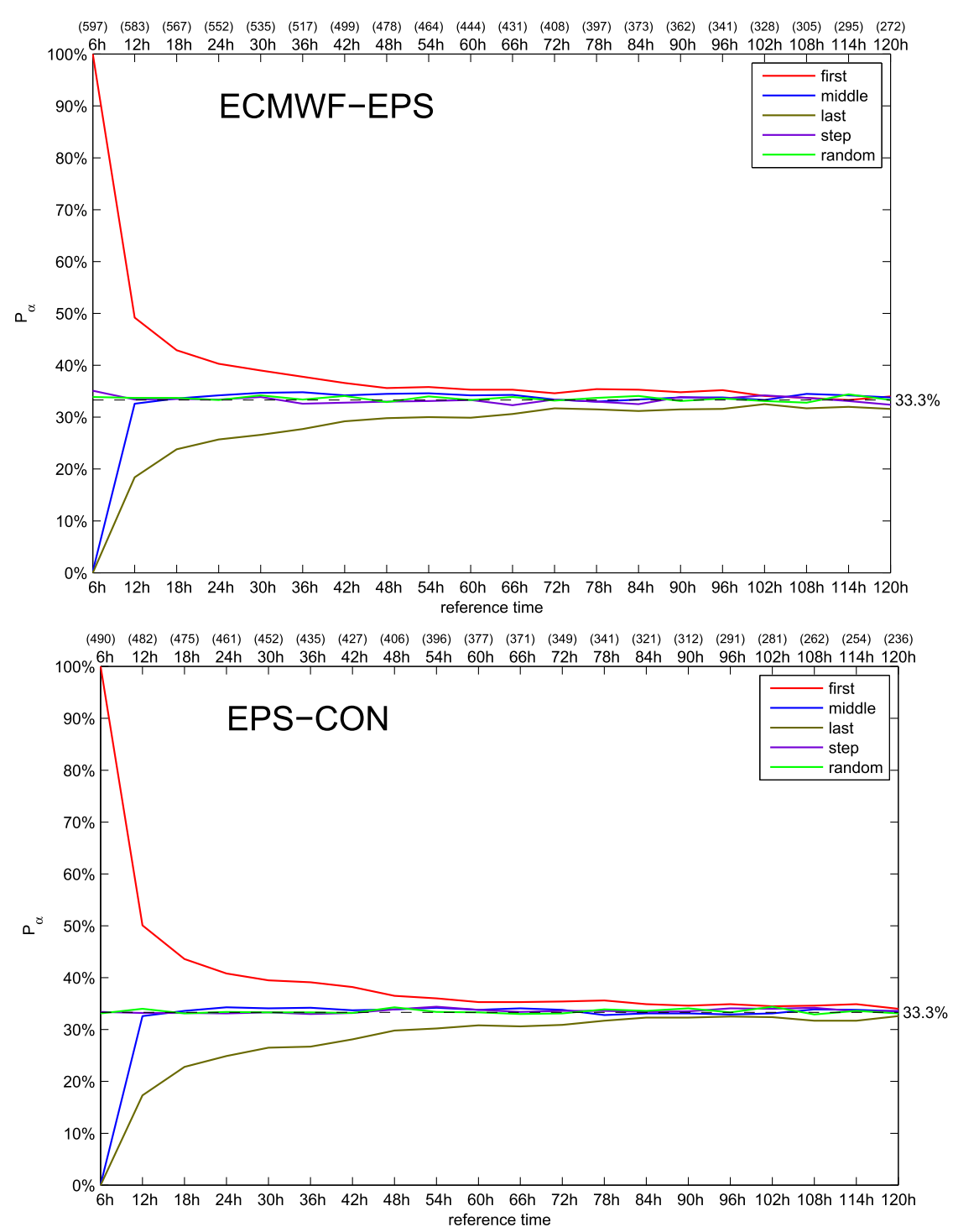

FIG. 4. The $P_{\alpha}$ of the five picking methods for (top) ECMWF-EPS and (bottom) EPS-CON when the reference time is $6 \mathrm{~h}$ and $\alpha=1 / 3$. The numbers in the parentheses are the sample sizes at different lead times.

Table 3 shows the hit ratio and major-minor axes of the $70 \%$ probability ellipse. With regard to ellipse size, in general the smallest was that of NCEP-GEFS, followed by that of ECMWF-EPS, and that of EPS-CON is slightly larger than that of ECMWF-EPS. As for the hit ratio, the descending order is EPS-CON, ECMWF-EPS, and NCEP-GEFS. Since the larger the ellipse, the more likely that an observation is to fall into it, the highest hit ratio of EPS-CON may be due to its larger size, which also indicates that the concentration areas of the ECMWF-EPS and NCEP-GEFS forecasts are different, in line with the conclusions we have drawn in section 3b.

In EPS-CON each ensemble member from each model is given the same weight, so the consensus is therefore more weighted toward ECMWF-EPS, which contains more members. Since the ensemble size of ECMWFEPS is larger than that of NCEP-GEFS, NCEP-GEFS can be regarded as an adjustment to the forecasts of ECMWF-EPS. As a result, the hit ratios and ellipse sizes of EPS-CON are closer to those of ECMWF-EPS than those of NCEP-GEFS in Table 3. The hit ratios of ECMWF-EPS are all above $80 \%$, which are larger than the theoretical $70 \%$, and unlike the improvements seen in the mean position errors shown in Table 2, the adjustments in the probability ellipse are superfluous considering the increase in ellipse size. Therefore, the uncertainty information drawn from ECMWF-EPS is quite representative. Note that the "real" (instead of 


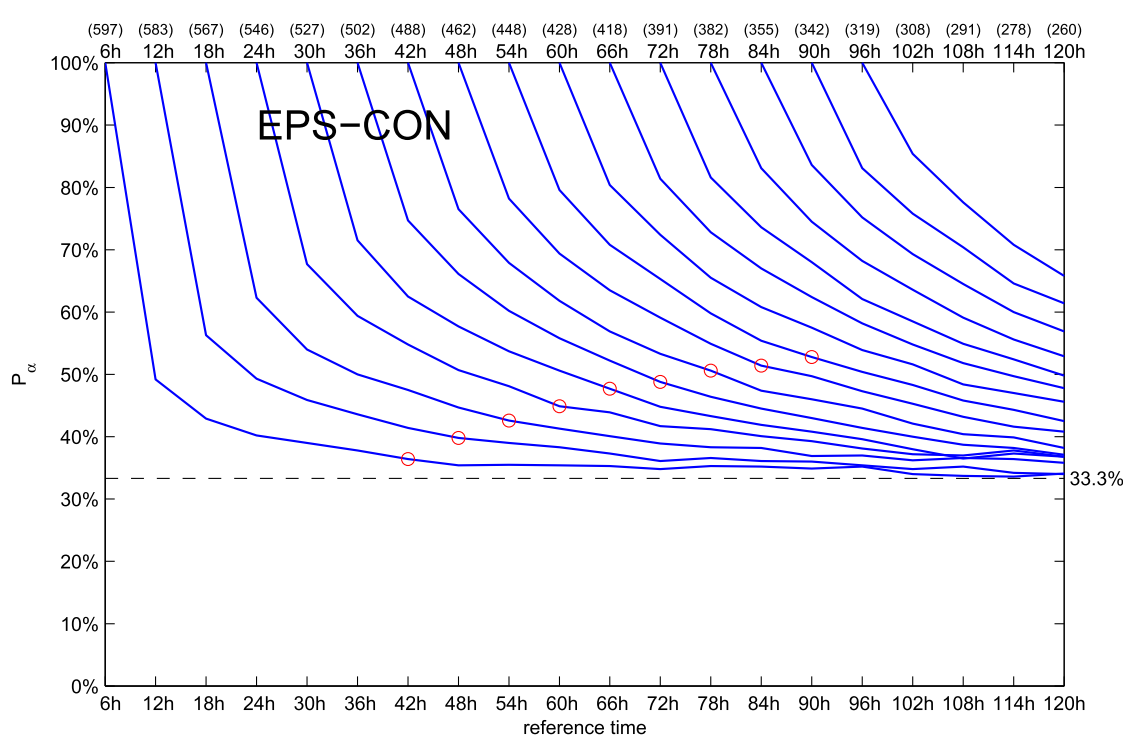

FIG. 5. The $P_{\alpha}$ at different reference times for ECMWF-EPS when $\alpha=1 / 3$. The red circles are $P_{\alpha}$ at $30 \mathrm{~h}$ from the reference time. The numbers in parentheses are the sample sizes at different lead times.

theoretical) $70 \%$ probability ellipse can be obtained by reducing the ellipse size; more specifically, the result can be achieved by increasing $\sigma$ in section $2 \mathrm{~b}$ mathematically.

Besides uncertainty information from the ensemble's size, the rotation angle relative to the forecast mean track and eccentricity of the ellipse also convey important uncertainty information (X. P. Zhang et al. 2015). More specifically, a smaller angle indicates relatively large uncertainty in the translation speed and confidence in the direction of movement, while a large angle indicates uncertainty in the direction of movement but greater confidence in the translation speed. Speed uncertainty is critical to the landing time, while direction uncertainty affects the landing area. In Fig. 3, two example diagrams of the $70 \%$ probability ellipse are shown with the track uncertainty of the left case larger. The right case, with a smaller rotation angle, indicates speed uncertainty while the left case, with a larger rotation angle, indicates directional uncertainty, especially after $84 \mathrm{~h}$. The case-dependent estimates of these uncertainties provided by the probability ellipses provide important information for decision-making.

\section{Impacts of member selection on EPS means and spreads}

EPS member selection techniques are now widely used (Qi et al. 2014; Qian et al. 2014; Yamaguchi et al. 2012). In operations, because of data communication and computational requirements, EPS products often reach forecasters with a delay time longer than $6 \mathrm{~h}$, when the latest observations are available to evaluate the performance at short lead times. By making use of these new observations, some member selection techniques are based on the premise that members with smaller errors at short

TABLE 4. Mean track error ( $\mathrm{km})$ for ECMWF-EPS after the first member picking using different picking ratios. The boldface text indicates the smallest number for each prediction time, and the numbers in parentheses are as in Table 2.

\begin{tabular}{|c|c|c|c|c|c|c|c|c|c|c|}
\hline Time & $\frac{12 \mathrm{~h}}{(589)}$ & $\frac{24 \mathrm{~h}}{(557)}$ & $\frac{36 \mathrm{~h}}{(521)}$ & $\frac{48 \mathrm{~h}}{(484)}$ & $\frac{60 \mathrm{~h}}{(449)}$ & $\frac{72 \mathrm{~h}}{(411)}$ & $\frac{84 \mathrm{~h}}{(377)}$ & $\frac{96 \mathrm{~h}}{(343)}$ & $\frac{108 \mathrm{~h}}{(308)}$ & $\frac{120 \mathrm{~h}}{(277)}$ \\
\hline Error $_{1 / 6}$ & 40.3 & 62.9 & 87.0 & 115.2 & 144.8 & 170.9 & 195.6 & 232.0 & 280.4 & 330.7 \\
\hline Error $_{2 / 6}$ & 41.5 & 62.1 & 85.4 & 112.8 & 142.1 & 166.5 & 190.9 & 227.6 & 276.4 & 323.7 \\
\hline Error $_{3 / 6}$ & 43.3 & 63.1 & 86.0 & 112.4 & 140.8 & 166.0 & 191.4 & 226.4 & 276.6 & 322.1 \\
\hline Error $_{4 / 6}$ & 44.8 & 63.7 & 87.1 & 112.6 & 141.0 & 165.7 & 191.4 & 227.1 & 274.1 & 320.1 \\
\hline Error $_{5 / 6}$ & 46.7 & 66.0 & 88.2 & 113.2 & 141.3 & 165.7 & 191.5 & 225.8 & 273.7 & 321.4 \\
\hline Error $_{6 / 6}$ & 49.2 & 67.5 & 89.7 & 113.8 & 142.4 & 166.1 & 192.5 & 226.4 & 273.9 & 322.7 \\
\hline $\operatorname{Max}-\min$ & 8.9 & 5.4 & 4.3 & 2.8 & 4.0 & 5.2 & 4.7 & 6.2 & 6.7 & 10.5 \\
\hline
\end{tabular}


TABLE 5. As in Table 4, but for EPS-CON.

\begin{tabular}{|c|c|c|c|c|c|c|c|c|c|c|}
\hline & $12 \mathrm{~h}$ & $24 \mathrm{~h}$ & $36 \mathrm{~h}$ & $48 \mathrm{~h}$ & $60 \mathrm{~h}$ & $72 \mathrm{~h}$ & $84 \mathrm{~h}$ & $96 \mathrm{~h}$ & $108 \mathrm{~h}$ & $120 \mathrm{~h}$ \\
\hline Time & $(482)$ & (461) & (434) & (405) & (377) & (348) & (318) & (289) & (259) & (235) \\
\hline Error $_{1 / 6}$ & 32.0 & 56.2 & 78.8 & 109.7 & 139.4 & 167.5 & 196.0 & 229.3 & 276.0 & 335.6 \\
\hline Error $_{2 / 6}$ & 32.0 & 54.7 & 76.8 & 105.4 & 134.8 & 162.3 & 189.9 & 223.4 & 270.5 & 325.6 \\
\hline Error $_{3 / 6}$ & 32.9 & 53.9 & 75.6 & 102.6 & 130.7 & 158.2 & 185.2 & 217.6 & 263.3 & 316.4 \\
\hline Error $_{4 / 6}$ & 34.5 & 54.4 & 76.0 & 101.9 & 129.6 & 156.4 & 182.7 & 215.5 & 259.1 & 311.7 \\
\hline Error $_{5 / 6}$ & 36.1 & 55.7 & 76.7 & 102.1 & 128.7 & 155.5 & 181.0 & 212.2 & 256.4 & 308.7 \\
\hline Error $_{6 / 6}$ & 39.1 & 57.8 & 78.3 & 102.2 & 128.2 & 155.0 & 179.7 & 211.1 & 254.3 & 305.9 \\
\hline $\operatorname{Max}-\min$ & 7.1 & 4.0 & 3.2 & 7.8 & 11.2 & 12.5 & 16.3 & 18.2 & 21.7 & 29.7 \\
\hline
\end{tabular}

lead times ( 6 or $12 \mathrm{~h}$ ) have smaller errors at the following lead times (Qi et al. 2014; Qian et al. 2014). In this section the relationship between errors at the reference lead time and the following lead times will be investigated. The evaluation in section 3 has shown that the performance of NCEP-GEFS is not as good as that of ECMWF-EPS and EPS-CON on the whole; thus, only the ECMWF-EPS and EPS-CON ensembles will be discussed in this section.

As in operations, not all the ensemble members will forecast at each prediction time; only when the number of forecast members exceeds 10 does it count as a forecast case.

\section{a. Relationship between errors at a reference lead time and the following lead times}

An index $P_{\alpha}$ is defined to evaluate the relationship between the error at the reference lead time $T_{\text {refer }}$ and that at the following lead time $T_{\text {long }}$. And $P_{\alpha}$ for a specific forecast case is calculated by the following steps:

1) using the best-track data, calculate the position error of each member at $T_{\text {refer }}$ and $T_{\text {long; }}$;

2) sort the EPS members in ascending order according to their position errors at $T_{\text {refer }}$ and $T_{\text {long }}$, respectively;
3) pick $\alpha$ percent members at $T_{\text {refer }}$ and refer to them as the "selected members"; and

4) check their performance at $T_{\text {long }}$ :

- count the selected members, which appear at $T_{\text {long }}$ and refer to the number as $N_{d}$;

- count how many of the selected members appear in the top $N_{d}$ of the sorted $T_{\text {long }}$ member list and refer to the number as $N_{u}$; and

- $P_{\alpha}=N_{u} / N_{d}$.

If the members chosen at $T_{\text {refer }}$ perform well at $T_{\text {long }}$, $P_{\alpha}$ will approach $100 \%$, and the track forecast error would be reduced effectively.

As for the picking method, Qi et al. (2014) and Qian et al. (2014) prefer the members with smaller position errors, which are the first $\alpha$ percent of the sorted $T_{\text {refer }}$ member list. Besides the first $\alpha$ percent, the middle and last $\alpha$ percent are also adopted to test $P_{\alpha}$. In addition, $P_{\alpha}$ is also calculated when EPS members at $T_{\text {refer }}$ are chosen uniformly and randomly. They are referred to as "first," "middle," "last," "step," and "random," respectively. If the errors at the reference time and the following lead times are related, the $P_{\alpha}$ of the first method will get the highest score; otherwise, $P_{\alpha}$ might approximate $\alpha$.
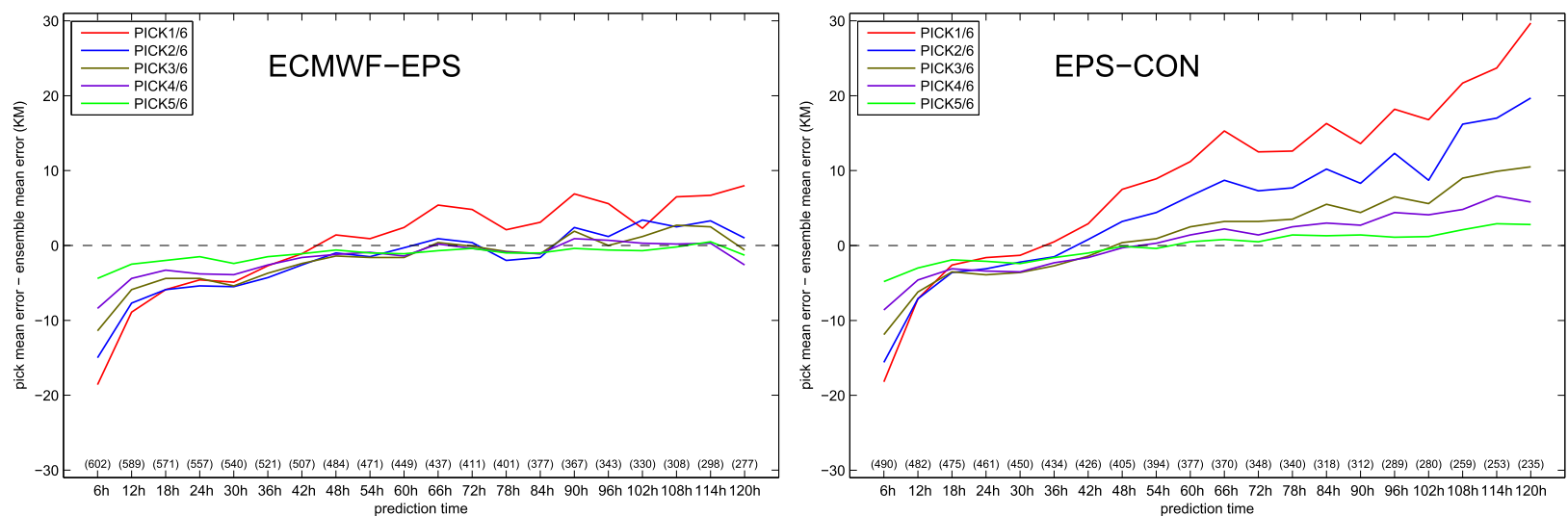

FIG. 6. The deviation of the mean track error from the ensemble mean error for (left) ECMWF-EPS and (right) EPS-CON after the first member picking when using different picking ratios. 

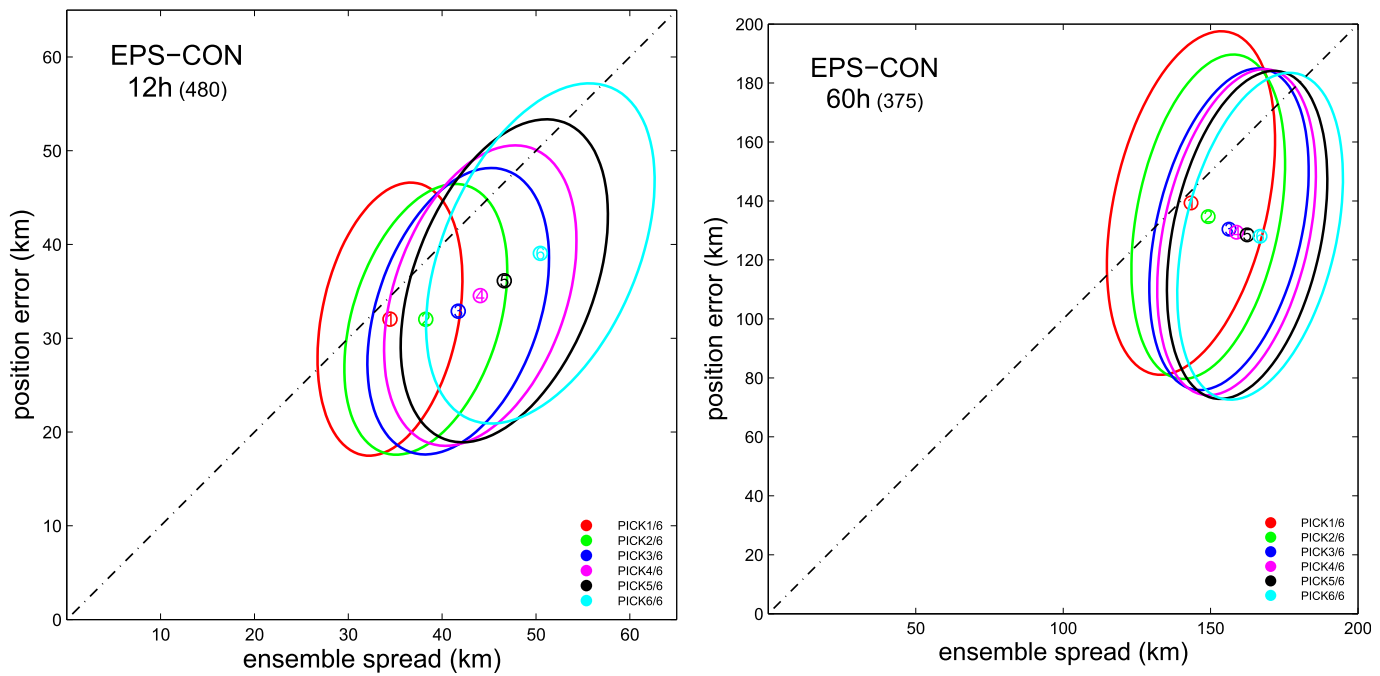

FIG. 7. The ensemble spread and position error at prediction times of (left) 12 and (right) $60 \mathrm{~h}$ for EPS-CON at different picking ratios. The ellipse contains about $20 \%$ of the samples at each prediction time.

Here, the experiment for ECMWF-EPS is shown in the top panel in Fig. 4. The reference time is set to $6 \mathrm{~h}$, $\alpha=1 / 3 \approx 0.3333$, and $P_{\alpha}$ at each prediction time is the average of all cases. We can see that the values of $P_{\alpha}$ are not exactly the same among the five selective methods at every prediction time; however, all of them approach $1 / 3$ as the prediction time evolves from 12 to $120 \mathrm{~h}$. The
$P_{\alpha}$ values of the middle, step, and random methods stay near $1 / 3$ (the theoretical value) from $12 \mathrm{~h}$ (the prediction time next to the reference time) to $120 \mathrm{~h}$, and middle is slightly better than the other two cases. Comparing first with last methods, apparent differences are observed before $60 \mathrm{~h}$, which are larger than $5 \%$. Up to and including $96 \mathrm{~h}$ the performance of first is the best

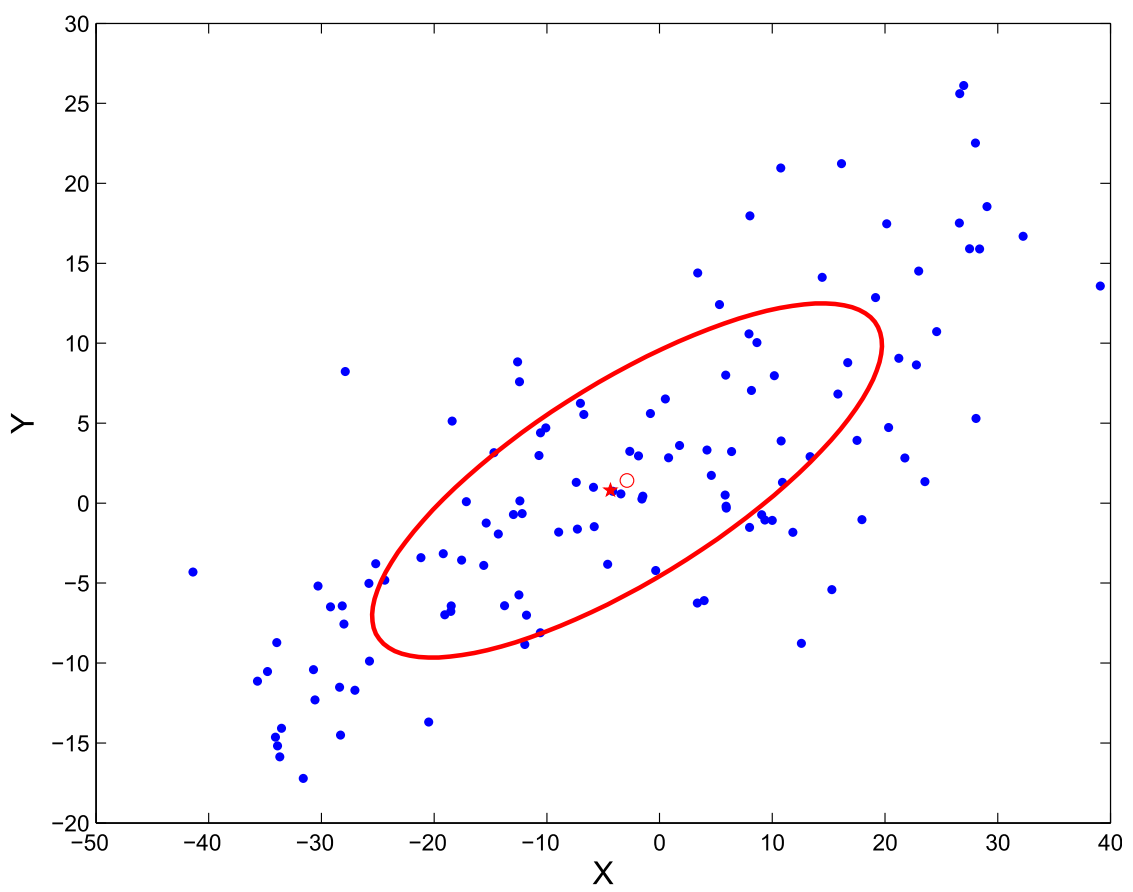

FIG. 8. Schematic diagram of ellipse selection. The blue dots are ensemble members, the small red circle is the ensemble mean, and the red star is the mean of the ensemble members located in the $50 \%$ probability ellipse. After ellipse selection, we obtain the red star, which is the revised version of the ensemble mean. 
TABLE 6. Mean track error $(\mathrm{km})$ for ECMWF-EPS after the refe (the first line of each row) and self (the second line of each row) ellipse selections $(40 \%-100 \%$, with an interval of $10 \%)$ for prediction times after $48 \mathrm{~h}$. The boldface text indicates the best values for refe and self at each prediction time. The numbers in parentheses are as in Table 2.

\begin{tabular}{|c|c|c|c|c|c|c|c|}
\hline \multirow{2}{*}{\multicolumn{2}{|c|}{ Time }} & $60 \mathrm{~h}$ & $72 \mathrm{~h}$ & $84 \mathrm{~h}$ & $96 \mathrm{~h}$ & $108 \mathrm{~h}$ & $120 \mathrm{~h}$ \\
\hline & & (449) & (413) & (376) & $(344)$ & (308) & (275) \\
\hline \multirow{2}{*}{ Error $_{40 \%}$} & \multirow{2}{*}{$\begin{array}{l}\text { refe } \\
\text { self }\end{array}$} & \multirow{2}{*}{142.8} & 167.8 & 192.2 & 226.6 & 269.8 & 316.0 \\
\hline & & & 167.6 & 190.5 & 227.7 & 272.2 & 318.0 \\
\hline \multirow{2}{*}{ Error $_{50 \%}$} & refe & \multirow{2}{*}{142.4} & 167.1 & 190.9 & 225.7 & 269.9 & 315.1 \\
\hline & self & & 166.7 & 190.7 & 229.8 & 271.9 & 316.4 \\
\hline \multirow{2}{*}{ Error $_{60 \%}$} & refe & \multirow{2}{*}{141.7} & 166.2 & 190.2 & 226.3 & 271.7 & 316.9 \\
\hline & self & & 166.4 & 191.5 & 229.6 & 271.4 & 318.2 \\
\hline \multirow{2}{*}{ Error $_{70 \%}$} & refe & \multirow{2}{*}{141.4} & 166.3 & 190.2 & 226.8 & 271.2 & 317.1 \\
\hline & self & & 166.0 & 192.0 & 228.9 & 271.0 & 318.6 \\
\hline \multirow{2}{*}{ Error $_{80 \%}$} & refe & \multirow{2}{*}{141.3} & 167.0 & 191.7 & 228.3 & 272.8 & 318.2 \\
\hline & self & & 166.1 & 191.6 & 228.9 & 273.3 & 321.2 \\
\hline \multirow{2}{*}{ Error $_{90 \%}$} & refe & \multirow{2}{*}{141.5} & 166.6 & 191.5 & 228.4 & 273.3 & 318.9 \\
\hline & self & & 166.5 & 191.4 & 228.2 & 272.7 & 320.5 \\
\hline Error $_{100 \%}$ & & 142.0 & 167.0 & 191.7 & 228.1 & 273.1 & 319.8 \\
\hline
\end{tabular}

of the five cases, but its deviation from the theoretical value is less than $5 \%$ after $30 \mathrm{~h}$, which means that less than one additional selected member appears at $T_{\text {long }}$ (compared with $N_{u}$ ), and thus the advantage is not prominent. Although the errors at the reference time and the following lead times are unrelated, the first selection is a better choice than the other four cases before $96 \mathrm{~h}$. It is clear that the premise that members with smaller errors at short lead times usually have smaller errors at the following lead times is not appropriate for all lead times.

The bottom panel in Fig. 4 shows the case for EPS$\mathrm{CON}$, and the same trend is also observed clearly. In this case, the weak advantage of the first choice persists out to $120 \mathrm{~h}$. In both cases, the values of $P_{\alpha}$ for different methods approach $1 / 3$ after $78 \mathrm{~h}$, when the deviation is $2.1 \%$ or less. Thus, the difference between the five methods is negligible.

Reference times other than $6 \mathrm{~h}$ are also studied (Fig. 5). In Fig. 5, the reference time changes from 6 to $96 \mathrm{~h}$ with a 6-h interval, the selective method is set to be first, and $\alpha$ is again $1 / 3$. We can see that $P_{\alpha}$ decreases as prediction time increases, but with the reference time changing from 6 to $96 \mathrm{~h}$, the decrease rate slows down. Taking $P_{\alpha}$ at $30 \mathrm{~h}$ from the reference time as an example (red circles in Fig. 5), it is found that $P_{\alpha}=37.8 \%$ when the reference time is $6 \mathrm{~h}, P_{\alpha}=57.5 \%$ when the reference time is $60 \mathrm{~h}$, and $P_{\alpha}=61.4 \%$ when the reference time is $90 \mathrm{~h}$. Although errors at $6 \mathrm{~h}$ and those at the following lead times are unrelated, errors at lead times after $48 \mathrm{~h}$ are related to some extent, which is shown clearly in
TABLE 7. As in Table 6, but for EPS-CON.

\begin{tabular}{|c|c|c|c|c|c|c|c|}
\hline \multirow[b]{2}{*}{ Time } & & $60 \mathrm{~h}$ & $72 \mathrm{~h}$ & $84 \mathrm{~h}$ & $96 \mathrm{~h}$ & $108 \mathrm{~h}$ & $120 \mathrm{~h}$ \\
\hline & & (379) & (348) & (317) & (290) & (261) & (234) \\
\hline \multirow{2}{*}{ Error $_{40 \%}$} & refe & \multirow{2}{*}{128.9} & 156.2 & 179.4 & 213.3 & 256.7 & 305.1 \\
\hline & self & & 156.9 & 178.8 & 214.6 & 257.3 & 302.9 \\
\hline \multirow{2}{*}{ Error $_{50 \%}$} & refe & \multirow{2}{*}{129.0} & 155.7 & 178.1 & 211.5 & 254.5 & 303.0 \\
\hline & self & & 156.3 & 178.8 & 214.0 & 258.0 & 301.9 \\
\hline \multirow{2}{*}{ Error $_{60 \%}$} & refe & \multirow{2}{*}{128.7} & 156.0 & 178.2 & 211.8 & 255.3 & 303.1 \\
\hline & self & & 155.8 & 177.9 & 213.2 & 256.4 & 302.1 \\
\hline \multirow{2}{*}{ Error $_{70 \%}$} & refe & \multirow{2}{*}{128.3} & 154.6 & 177.0 & 210.9 & 255.4 & 302.3 \\
\hline & self & & 155.2 & 177.3 & 212.1 & 256.0 & 302.9 \\
\hline \multirow{2}{*}{ Error $_{80 \%}$} & refe & \multirow{2}{*}{127.5} & 154.2 & 176.6 & 211.5 & 255.4 & 303.0 \\
\hline & self & & 154.2 & 177.1 & 211.5 & 255.9 & 303.0 \\
\hline \multirow{2}{*}{ Error $_{90 \%}$} & refe & \multirow{2}{*}{127.5} & 154.6 & 176.8 & 211.4 & 256.0 & 302.3 \\
\hline & self & & 154.3 & 176.4 & 212.0 & 255.6 & 303.6 \\
\hline Error $_{100 \%}$ & & 128.1 & 154.7 & 177.0 & 211.2 & 255.8 & 303.2 \\
\hline
\end{tabular}

Fig. 5. If member selection in the medium time range (e.g., $48 \mathrm{~h}$ ) can be optimized, the forecast errors after $72 \mathrm{~h}$ may be reduced. Nevertheless, in general new model runs initialized at later times are available by the time these errors can be calculated, and the new runs would usually be more accurate. The lead time errors within $48 \mathrm{~h}$ may be more influenced by the initial conditions, while the lead time errors after $48 \mathrm{~h}$ may be more affected by the dynamics, boundary conditions, and parameterizations of the numerical model.

As discussed above, errors at short lead times (6 or $12 \mathrm{~h}$ ) and at the following lead times are unrelated; that is to say, it is impossible to pick members whose position errors are smaller for all prediction times, but the first method is a good choice for some short time ranges (e.g., within $48 \mathrm{~h}$ ). The member picking method for long time ranges after $48 \mathrm{~h}$ should not be based on position errors at short lead times, while member picking based on medium lead times $(48 \mathrm{~h})$ is quite unrealistic in operational applications.

\section{b. Impact of the picking ratio}

In this section, the picking ratio $\alpha$ will be studied. The first method based on the position error at a prediction time of $6 \mathrm{~h}$ is adopted, and the ratio $\alpha$ is set to vary between $1 / 6$ and 1 with an interval of $1 / 6$. The position errors for ECMWF-EPS and EPS-CON are shown in Tables 4 and 5, respectively. The boldface numbers are the smallest values in each column, and the bottom row "max - min" indicates the difference between the maximum and minimum values of each column.

The position errors differ for different ratios at the same prediction time. For ECMWF-EPS (see Table 4 and Fig. 6), the 12-h error decreases by $9 \mathrm{~km}$ when adopting $\alpha=1 / 6$, but when the prediction time 

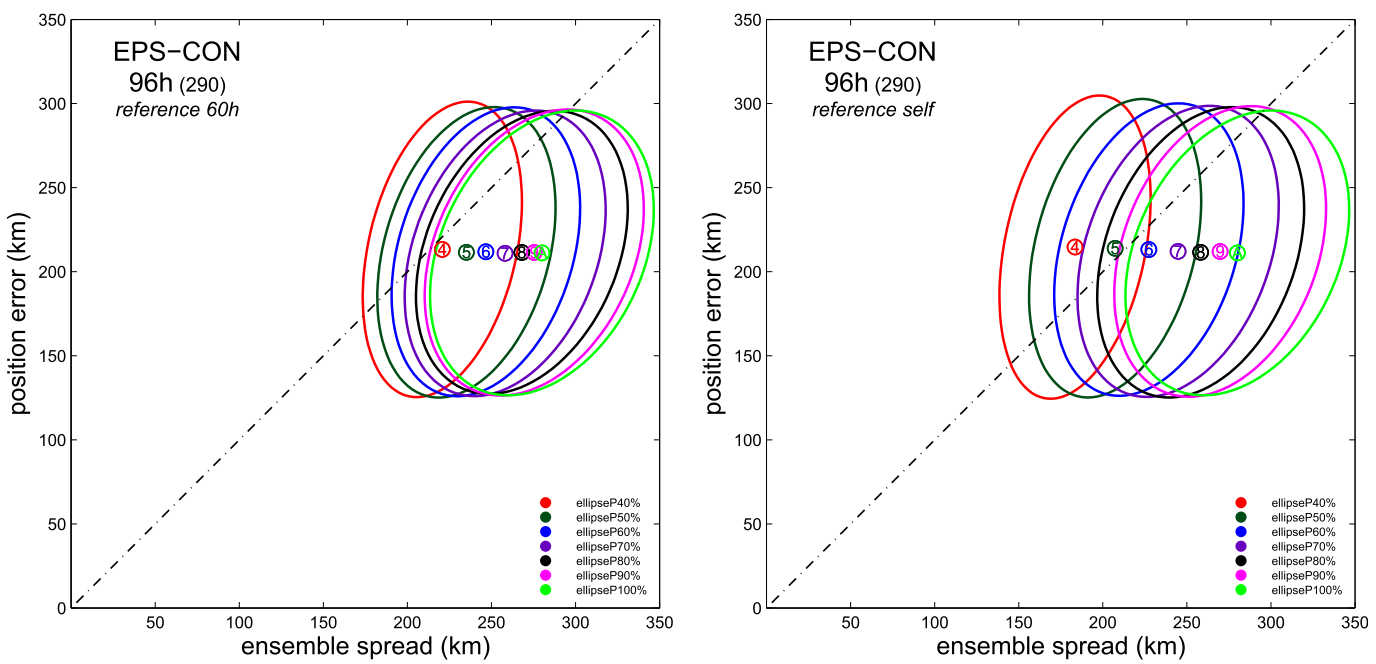

FIG. 9. The ensemble spread and position error at prediction time $96 \mathrm{~h}$ for the (left) refe and (right) self ellipse selections for EPS-CON. The ellipse contains about $20 \%$ of the samples at each prediction time.

increases, the advantage of $\alpha=1 / 6$ diminishes, and after $36 \mathrm{~h}$ it is surpassed by the other $\alpha$ values adopted in this table. The full choice $(\alpha=6 / 6)$ is not as good as the others at lead times within $48 \mathrm{~h}$; however for lead times longer than that, its advantage starts to appear. In Table 5 and Fig. 6 for EPS-CON, the trends are clear cut. It is shown that the advantage of member picking based on 6-h position error is obvious only before $48 \mathrm{~h}$, at which point the position error increases as the picking ratio decreases. This reinforces the earlier findings that member selection is only beneficial for track forecasts within $48 \mathrm{~h}$. Comparing Tables 4 and 5, the value $\alpha=3 / 6$ is found to be better in both tables within $48 \mathrm{~h}$. Thus, $\alpha=1 / 2$ will be chosen as the picking ratio within $48 \mathrm{~h}$, which is similar to the prior finding of Qi et al. (2014).

In Fig. 7 the relationships between SPRD and Perror are shown for 12 and $60 \mathrm{~h}$. Unlike that in section $3 \mathrm{~b}$, the SPRD values are calculated whenever there is more than one member for the available forecast. For $12 \mathrm{~h}$, the ensemble spread and position errors both increase with picking ratios, and the smaller the picking ratio, the more concentrated are the cases in the SPRD-Perror plot. For $60 \mathrm{~h}$, the ensemble spreads increase slightly with picking ratio, and the sizes of the concentration areas are closer to each other, while the mean position error decreases.

This short-time- $(6 \mathrm{~h})$ based picking method is superfluous for lead times after $48 \mathrm{~h}$. Qian et al. (2014) changed the picking number for different prediction times with the first picking, which is not efficient, as shown in Tables 4 and 5. Because of the lack of correlation between EPS errors at the short and following lead times, the picking method for lead times after $48 \mathrm{~h}$ should be different from that for lead times within $48 \mathrm{~h}$.

\section{c. The ellipse selection for medium and long lead times}

In the last section it is found that track forecasts after $48 \mathrm{~h}$ cannot be improved by member selection based on short lead time errors at $6 \mathrm{~h}$; thus, it is difficult to identify better ensemble members for prediction times after $48 \mathrm{~h}$. Figure 5 shows that these errors may be reduced by optimizing the medium lead time members (e.g., at $48 \mathrm{~h}$ ). Since there is no observation available when doing the forecasts, it is impossible to select members within the short lead time range.

In this section the selections at lead times after $48 \mathrm{~h}$ are performed under the premise that a TC is expected

TABLE 8. Improvements in the ensemble mean (\%) after $6 \mathrm{~h}$ of shifting compared with the ensemble mean. The numbers in parentheses are as in Table 2.

\begin{tabular}{lccccccccccc}
\hline \hline \multicolumn{1}{c}{ EPS } & $\frac{12 \mathrm{~h}}{(486)}$ & $\frac{24 \mathrm{~h}}{(465)}$ & $\frac{36 \mathrm{~h}}{(439)}$ & $\frac{48 \mathrm{~h}}{(410)}$ & $\frac{60 \mathrm{~h}}{(381)}$ & $\frac{72 \mathrm{~h}}{(353)}$ & $\frac{84 \mathrm{~h}}{(325)}$ & $\frac{96 \mathrm{~h}}{(295)}$ & $\frac{108 \mathrm{~h}}{(265)}$ & $\frac{120 \mathrm{~h}}{(239)}$ \\
\hline ECMWF-EPS & 25.7 & 10.0 & 6.0 & 3.6 & 0.9 & 0.6 & -0.4 & -1.0 & -1.4 & -1.6 \\
NCEP-GEFS & 23.9 & 5.8 & 3.1 & 1.5 & 1.3 & 1.3 & 0.8 & 0.2 & -0.6 & -1.0 \\
EPS-CON & 23.5 & 8.3 & 3.3 & 2.0 & 0.7 & 0.9 & 0.6 & 0.1 & -0.7 & -1.4 \\
\hline
\end{tabular}


TABLE 9. As in Table 8, but for the selective mean.

\begin{tabular}{lcccccccccccc}
\hline \hline \multicolumn{1}{c}{ EPS } & $\frac{12 \mathrm{~h}}{(482)}$ & $\frac{24 \mathrm{~h}}{(461)}$ & $\frac{36 \mathrm{~h}}{(435)}$ & $\frac{48 \mathrm{~h}}{(406)}$ & $\frac{60 \mathrm{~h}}{(381)}$ & $\frac{72 \mathrm{~h}}{(353)}$ & $\frac{84 \mathrm{~h}}{(325)}$ & $\frac{96 \mathrm{~h}}{(295)}$ & $\frac{108 \mathrm{~h}}{(265)}$ & $\frac{120 \mathrm{~h}}{(239)}$ \\
\hline ECMWF-EPS & 27.3 & 10.7 & 7.0 & 1.9 & 1.4 & 1.0 & -0.2 & -0.8 & -1.3 & -1.4 \\
NCEP-GEFS & 21.4 & 4.1 & 1.8 & -0.6 & 1.3 & 1.1 & 0.7 & 0.2 & -0.4 & -0.7 \\
EPS-CON & 26.1 & 9.4 & 3.9 & 0.5 & 1.4 & 1.2 & 0.8 & 0.3 & -0.3 & -0.7 \\
\hline
\end{tabular}

to be located in the concentration area of forecast positions, which is the same premise used for extracting probability information. The concentration area is determined by the probability circle, within which a TC is expected to be located with a certain possibility.

Figure 8 is a schematic diagram of the "ellipse" selection. First, a probability ellipse is drawn based on the ensemble spread, then the dots within it are chosen, and finally the average of the dots is calculated as the improved version of the ensemble mean.

Tables 6 and 7 are position errors of ellipse selections for ECMWF-EPS and EPS-CON. The "refe" line denotes that the member selections after and including $60 \mathrm{~h}$ are based on the ellipse selection at $60 \mathrm{~h}$, while the "self" line denotes that the member selections are based on the ellipse selection at each prediction time itself. In these tables the boldface numbers are the best value of refe and self at each prediction time. In both tables, it is shown that the differences between refe and self are almost negligible, and the track forecasts have not been improved significantly by the ellipse member picking. Figure 9 depicts the relationship between SPRD and Perror for the refe and self ellipse selections, and the value of SPRD is calculated when there is more than one member for an available forecast. In both cases the ensemble spread increases as the ellipse proportion varies from $40 \%$ to $100 \%$, while the position error remains relatively stable. Furthermore, the sizes of the concentration

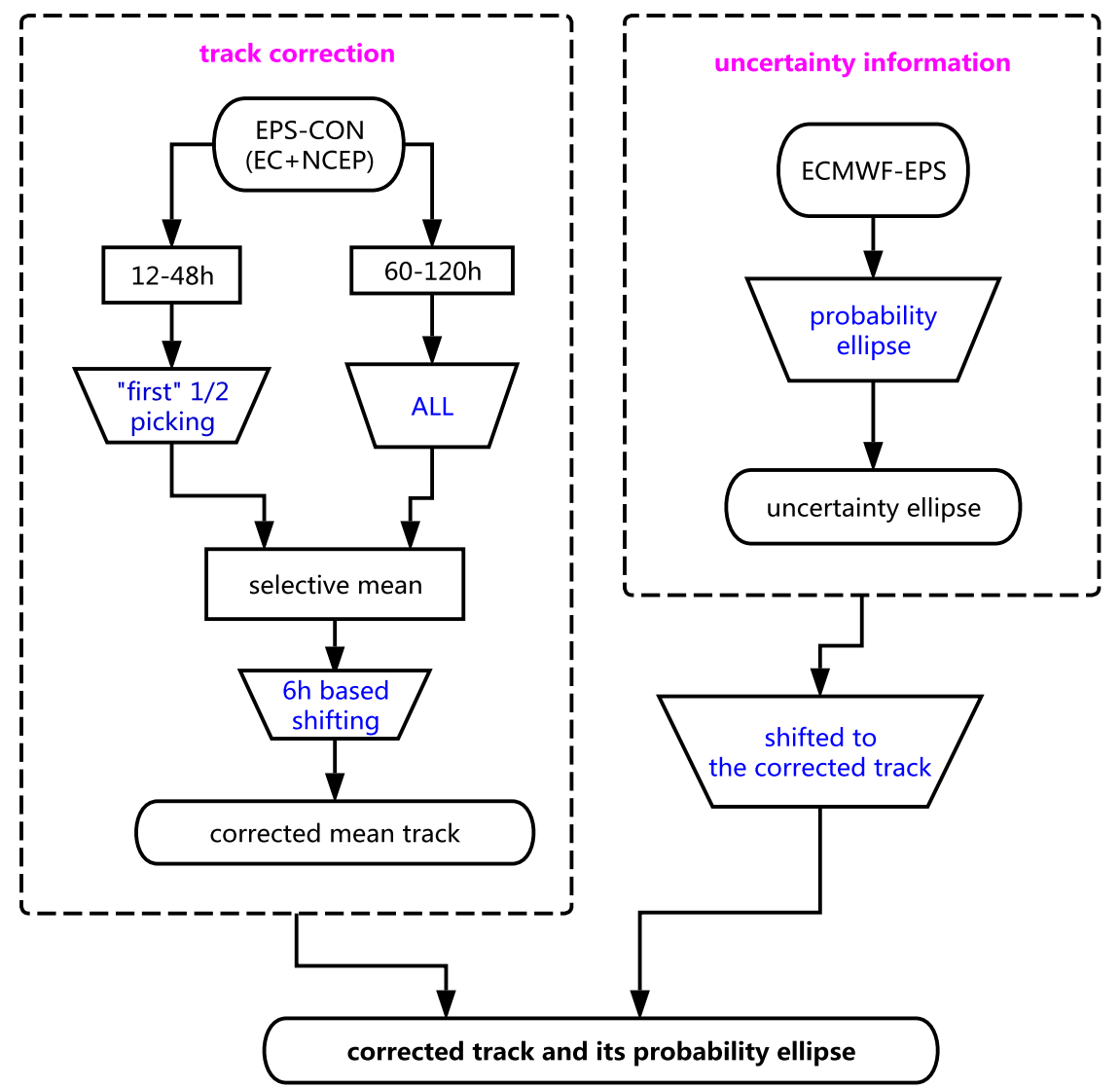

FIG. 10. Flowchart showing the proposed scheme. The main techniques are highlighted in blue. 


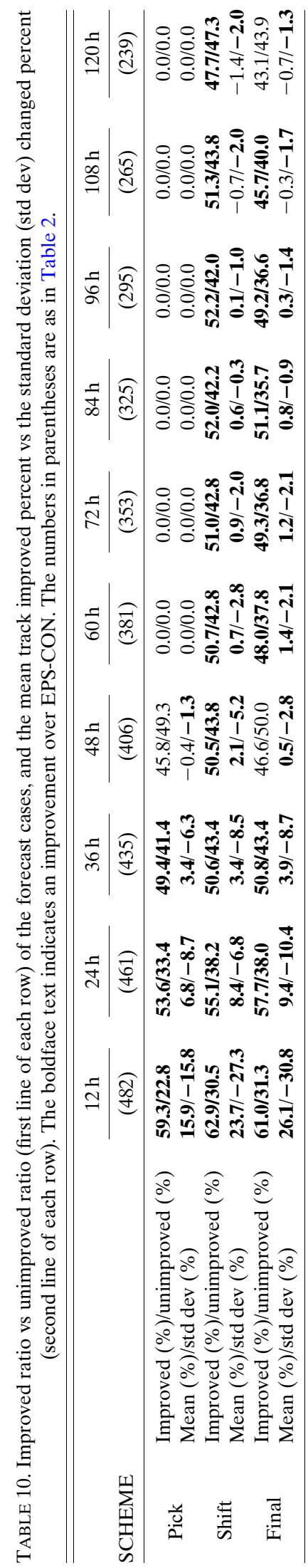

areas are closer to each other, implying that the ellipse picking makes only a small adjustment to the system. With the development of a numerical simulation, it may be more likely for a TC to be located in the concentration area of forecast dots, and the assumption of self may be more reasonable for lead times after $48 \mathrm{~h}$ in the future.

Therefore, for forecasts after $48 \mathrm{~h}$, position errors are determined largely by the performance of the EPS, and the position errors cannot be further reduced efficiently by member picking. The superensemble of several EPSs chosen based on verification, like EPS-CON, is a much better choice than picking. Therefore, it is not suggested that member picking be done for forecasts after $48 \mathrm{~h}$.

\section{Impacts of horizontal shifting on EPS means}

The member selective technique for a short lead time $(6 \mathrm{~h})$ is based on the time delay of EPS products. Since the latest observation (at the 6-h prediction time) is already available, a simple shift may improve the track forecasts (Qi et al. 2014). Here, we study to what extent the horizontal shift can improve the deterministic track forecasts.

The tracks chosen for shifting include the ensemble mean and selective mean. The selective mean denotes the mean of the first $1 / 2$ member picking within $48 \mathrm{~h}$.

Table 8 compares the ensemble mean (Table 2) with its 6-h shifting version. It is found that the shifting effect decays with time. Before $48 \mathrm{~h}$ the position error decreases obviously. For example, for $12 \mathrm{~h}$ the position error decreases are about $25.7 \%, 23.9 \%$, and $23.5 \%$ for ECMWF-EPS, NCEP-GEFS, and EPS-CON, respectively. However after $72 \mathrm{~h}$ the position errors even increase a bit. Table 9 compares the ensemble mean with the selective mean method after $6 \mathrm{~h}$ of shifting. We can see that shifting cannot bring down errors after $84 \mathrm{~h}$, which is consistent with the inherent nonlinearity of the numerical models.

\section{The proposed scheme}

Since the atmosphere is a highly nonlinear dynamic system sensitive to its initial values, it is impossible to calculate the exact state of the atmosphere far into the future even if the atmosphere is "completely" observed. The EPS plays an important role in the track forecasts of $\mathrm{TC}$, because it can be used to quantity this uncertainty compared with deterministic models.

The uncertainty information and the selective consensus based on the superensemble of ECMWF-EPS and NCEP-GEPS are discussed in the above sections. With regard to deterministic track improvement, three techniques are proposed and tested. It is found that the first $1 / 2$ member picking for prediction times within $48 \mathrm{~h}$ and horizontal shifting of the consensus of ECMWF-EPS and 
TABLE 11. The hit ratio (\%) comparison between ECMWF-EPS and the final scheme (EPS*). The numbers in parentheses are as in Table 2.

\begin{tabular}{lcccccccccccc}
\hline \hline \multicolumn{1}{c}{ EPS } & $\frac{12 \mathrm{~h}}{(568)}$ & $\frac{24 \mathrm{~h}}{(535)}$ & $\frac{36 \mathrm{~h}}{(494)}$ & $\frac{48 \mathrm{~h}}{(449)}$ & $\frac{60 \mathrm{~h}}{(416)}$ & $\frac{72 \mathrm{~h}}{(376)}$ & $\frac{84 \mathrm{~h}}{(338)}$ & $\frac{96 \mathrm{~h}}{(292)}$ & $\frac{108 \mathrm{~h}}{(265)}$ & $\frac{120 \mathrm{~h}}{(229)}$ \\
\hline ECMWF-EPS & 81.2 & 85.8 & 86.8 & 88.6 & 92.1 & 92.3 & 89.6 & 90.1 & 89.4 \\
EPS* & 94.0 & 90.3 & 90.7 & 92.4 & 94.5 & 92.6 & 91.4 & 92.5 & 89.8 & 89.1 \\
\hline
\end{tabular}

NCEP-GEFS can be regarded as good choices for the mean track correction. As for probability forecasts, the uncertainty information obtained from ECMWF-EPS is representative; thus, shifting its ellipses to the corrected track is adopted. A flowchart outlining this process is shown in Fig. 10.

Some comparisons are shown in Tables 10 and 11 to evaluate the performance of techniques applied to the consensus EPS-CON.

Table 10 gives the improved/unimproved ratio of forecast cases (first line of each row), and the improved percent of mean track versus percent change of standard deviation (second line of each row) compared with EPSCON. The improved/unimproved case ratio is defined as the ratio of the forecast cases that show improvements/ deterioration over the ensemble mean compared to the total number of forecast cases. In addition, "pick" denotes the selective mean method ( $\alpha=1 / 2$ before $48 \mathrm{~h}$ ), "shift" denotes the 6-h-observation-based horizontal shifting method, and "final" denotes the final scheme as depicted in Fig. 10. To make the conclusions clearer, the improved situations are highlighted with boldface numbers in Table 10, and more attention should be paid to the second line of each row. For the proposed scheme at $24 \mathrm{~h}, 57 \%$ out of 461 cases have been improved, the mean track error is reduced by $9.4 \%$, and the ensemble spread is reduced by $10.4 \%$ compared with EPS-CON—results that are better than those of the first two schemes. While the final scheme struggles to reduce errors after $60 \mathrm{~h}$ in a deterministic way, it can effectively improve the forecasts within $48 \mathrm{~h}$.

In Table 11 the hit ratio for the probability ellipse is shown, and the improvements are obvious within $48 \mathrm{~h}$ (e.g., $4.5 \%$ improvement over the ECMWF-EPS at $24 \mathrm{~h}$ ). Afterward the improvements become negligible, given that the hit ratio after 3 days is mainly affected by the EPS performance and difficult to improve, like the short lead time error.

\section{Discussion}

In this paper, the possible techniques for TC track improvements in both deterministic and probabilistic methods utilizing EPSs are studied, and an optimal scheme is proposed.

First, the track forecasts of ECMWF-EPS, NCEPGEFS, and their grand ensemble during 2014 and 2015 are evaluated. It is found that the forecast concentration area of NCEP-GEPS deviates substantially from that of
ECMWF-EPS, and they often cancel each other to some extent. Thus, the consensus can reduce position errors, which has been verified by the evaluation. The probability ellipse is also studied. It is shown that the adjustments brought by the consensus are superfluous considering the increase in probability ellipse sizes, and the uncertainty information drawn from ECMWF-EPS is representative.

Three techniques are then employed to improve the ensemble track forecasts. An index is defined to evaluate the randomness of EPSs. It is found that for the errors after $48 \mathrm{~h}$, the ensemble members are unrelated to their short lead time errors ( $6 \mathrm{~h}$ ), but "first" picking (with the highest ranked members at the reference time) is always the best choice for prediction times within $48 \mathrm{~h}$. In particular, we found that picking can improve short lead time track forecasts, and $1 / 2$ of the member number is a good choice. By contrast, position errors after $48 \mathrm{~h}$ depend largely on the performance of the EPSs themselves, and thus the grand ensemble of several EPSs, such as EPS-CON in our study, is a much better choice than unsubstantiated picking. Finally, the latest observations due to time delay are used to shift the forecast track, and it is found that the horizontal shifting only works effectively within $48 \mathrm{~h}$.

The proposed scheme, which consists of a shifted selective mean track from the grand ensemble and probability ellipses from ECMWF-EPS, has improved the track forecasts from both deterministic and probabilistic perspectives. The proposed scheme shows a $10 \%$ improvement in the mean track forecast errors over the grand ensemble and a $4.5 \%$ improvement in the hit ratio of $70 \%$ probability ellipses over the ECMWF-EPS at $24 \mathrm{~h}$, demonstrating its good potential to be applied in operations. However the effectiveness of the scheme is not significant for lead times longer than $48 \mathrm{~h}$. In this study, we only focus on the EPSbased track forecast scheme, which can provide both deterministic and probabilistic information. Further studies are still needed to investigate the possible sources of the predictability of cyclone tracks in different models.

Acknowledgments. We are very grateful to Dr. Kevin Cheung from Macquarie University and the three anonymous reviewers for their helpful comments and feedback on this study. This study was supported by the National Basic Research Program of China (2015CB452806) and the Projects for Public Welfare (Meteorology) of China 
(GYHY201506007WMO-TLFDP), the Typhoon Scientific and Technological Innovation Group of Shanghai Meteorological Service, the National Natural Science Foundation of China under Grant 41675116, and a CMA Key Project of Meteorological Prediction [Grant YBGJXM(2017)06].

\section{REFERENCES}

Du, Y. G., L. B. Qi, and X. G. Cao, 2016: Selective ensemble-mean technique for tropical cyclone track forecast by using timelagged ensemble and multi-centre ensemble in the western North Pacific. Quart. J. Roy. Meteor. Soc., 142, 2452-2462, https://doi.org/10.1002/qj.2838.

Dupont, T., M. Plu, P. Caroff, and G. Faure, 2011: Verification of ensemble-based uncertainty circles around tropical cyclone track forecasts. Wea. Forecasting, 26, 664-676, https://doi.org/ 10.1175/WAF-D-11-00007.1.

Goerss, J. S., 2007: Prediction of consensus tropical cyclone track forecast error. Mon. Wea. Rev., 135, 1985-1993, https://doi.org/ 10.1175/MWR3390.1.

- C. R. Sampson, and J. M. Gross, 2004: A history of western North Pacific tropical cyclone track forecast skill. Wea. Forecasting, 19, 633-638, https://doi.org/10.1175/1520-0434(2004)019<0633: AHOWNP $>2.0 . \mathrm{CO} ; 2$.

Hamill, T. M., J. S. Whitaker, M. Fiorino, and S. G. Benjamin, 2011: Global ensemble predictions of 2009's tropical cyclones initialized with an ensemble Kalman filter. Mon. Wea. Rev., 139, 668-688, https://doi.org/10.1175/2010MWR3456.1.

_ , M. J. Brennan, B. Brown, M. DeMaria, E. N. Rappaport, and Z. Toth, 2012: NOAA's future ensemble-based hurricane forecast products. Bull. Amer. Meteor. Soc., 93, 209-220, https://doi.org/10.1175/2011BAMS3106.1.

He, C. F., X. F. Zhi, Q. L. You, B. Song, and K. Fraedrich, 2015 Multi-model ensemble forecasts of tropical cyclones in 2010 and 2011 based on the Kalman filter method. Meteor. Atmos. Phys., 127, 467-479, https://doi.org/10.1007/s00703-015-0377-1.

Jolliffe, I. T., and D. B. Stephenson, 2003: Forecast Verification: A Practitioner's Guide in Atmospheric Science. John Wiley and Sons, $157 \mathrm{pp}$

Krishnamurti, T. N., C. M. Kishtawal, Z. Zhang, T. LaRow, D. Bachiochi, E. Williford, S. Gadgil, and S. Surendran, 2000: Multimodel ensemble forecasts for weather and seasonal climate. J. Climate, 13, 4196-4216, https://doi.org/10.1175/ 1520-0442(2000)013<4196:MEFFWA > 2.0.CO;2.

_, S. Pattnaik, M. K. Biswas, E. Bensman, M. Kramer, N. Surgi, and T. V. Kumar, 2010: Hurricane forecasts with a mesoscale suite of models. Tellus, 62A, 633-646, https://doi.org/10.1111/ j.1600-0870.2010.00469.x.

Kunitsugu, M., 2012: Tropical cyclone information provided by the RSMC Tokyo-Typhoon Center. Trop. Cyclone Res. Rev., 1 , 51-59, https://doi.org/10.6057/2012TCRR01.06.

Lei, X. T., and H. Yu, 2015: The progress of WMO Typhoon Landfall Forecast Demonstration Project (in Chinese). $A d v$. Meteor. Sci. Technol., 2, 18-23.

Lorenz, E. N., 1995: The Essence of Chaos. University of Washington Press, 227 pp.

Majumdar, S. J., and P. M. Finocchio, 2010: On the ability of global ensemble prediction systems to predict tropical cyclone track probabilities. Wea. Forecasting, 25, 659-680, https://doi.org/ 10.1175/2009WAF2222327.1

Pedlosky, J., 1987: Geophysical Fluid Dynamics. 2nd ed. SpringerVerlag, $710 \mathrm{pp}$
Qi, L. B., H. Yu, and P. Y. Chen, 2014: Selective ensemble-mean technique for tropical cyclone track forecast by using ensemble prediction systems. Quart. J. Roy. Meteor. Soc., 140, 805-813, https://doi.org/10.1002/qj.2196.

Qian, Q. F., C. A. Zhang, S. Z. Gao, L. Zhang, and L. Dong, 2014: The real-time correction technology research for typhoon ensemble track forecast (in Chinese). J. Trop. Meteor., 30, 905-910.

Sampson, C. R., J. S. Goerss, and A. J. Schrader, 2005: A consensus track forecast for Southern Hemisphere tropical cyclones. Aust. Meteor. Mag., 54, 115-119.

Song, J. J., Y. Wang, and L. G. Wu, 2010: Trend discrepancies among three best track data sets of western North Pacific tropical cyclones. J. Geophys. Res., 115, D12128, https://doi.org/10.1029/ 2009JD013058.

Wang, C. X., 2014: Ensemble prediction of Typhoon Muifa's track and intensity (in Chinese). J. Trop. Oceanogr., 33 (6), 48-60.

Weigel, A. P., M. A. Liniger, and C. Appenzeller, 2008: Can multimodel combination really enhance the prediction skill of probabilistic ensemble forecasts? Quart. J. Roy. Meteor. Soc., 134, 241-260, https://doi.org/10.1002/qj.210.

Whitaker, J. S., and A. F. Loughe, 1998: The relationship between ensemble spread and ensemble mean skill. Mon. Wea. Rev., 126, 3292-3302, https://doi.org/10.1175/1520-0493(1998)126<3292: TRBESA $>2.0 . \mathrm{CO} ; 2$

WMO, 2015: TIGGE Cyclone Exchange. World Meteorological Organization, https://www.ecmwf.int/en/research/projects/tigge.

$\mathrm{Xu}, \mathrm{Q}$. Z., and S. Lu, 2004: Probability and Mathematical Statistics (in Chinese). Higher Education Press, 72 pp.

Yamaguchi, M., R. Sakai, M. Kyoda, T. Komori, and T. Kadowaki, 2009: Typhoon ensemble prediction system developed at the Japan Meteorological Agency. Mon. Wea. Rev., 137, 2592-2604, https://doi.org/10.1175/2009MWR2697.1.

_ , T. Nakazawa, and S. Hoshino, 2012: On the relative benefits of a multi-centre grand ensemble for tropical cyclone track prediction in the western North Pacific. Quart. J. Roy. Meteor. Soc., 138, 2019-2029, https://doi.org/10.1002/qj.1937.

Ying, M., W. Zhang, H. Yu, X. Q. Lu, J. X. Feng, Y. X. Fan, Y. T. Zhu, and D. Q. Chen, 2014: An overview of the China Meteorological Administration tropical cyclone database. J. Atmos. Oceanic Technol., 31, 287-301, https://doi.org/ 10.1175/JTECH-D-12-00119.1.

$\mathrm{Yu}, \mathrm{H}$., and Coauthors, 2012: Operational tropical cyclone forecast verification practice in the western North Pacific region. Trop. Cyclone Res. Rev., 1, 361-372, https://doi.org/10.6057/ 2012TCRR03.06.

Zhang, H. B., X. F. Zhi, J. Chen, Y. N. Wang, and Y. Wang, 2015: Study of the modification of multi-model ensemble schemes for tropical cyclone forecasts. J. Trop. Meteor., 21, 389, http:// www.cnki.net/kcms/doi/10.16555/j.1006-8775.2015.04.007.html.

Zhang, L., and X. F. Zhi, 2015: Multimodel consensus forecasting of low temperature and icy weather over central and southern China in early 2008. J. Trop. Meteor., 21, 67-75, http://www. cnki.net/kcms/doi/10.16555/j.1006-8775.2015.01.007.html.

Zhang, X. P., and Q. Zhao, 2016: Dynamics of Rossby dipole with effect of scalar nonlinearity. Commun. Nonlinear Sci., 32, 137-144, https://doi.org/10.1016/j.cnsns.2015.08.017.

- G. M. Chen, H. Yu, and Z. H. Zeng, 2015: Verification of ensemble track forecasts of tropical cyclones during 2014. Trop. Cyclone Res. Rev., 4 (2), 79-87, https://doi.org/10.6057/2015TCRR02.04.

Zhi, X. F., H. X. Qi, Y. Q. Bai, and C. Z. Lin, 2012: A comparison of three kinds of multimodel ensemble forecast techniques based on the TIGGE data. Acta Meteor. Sin., 26, 41-51, https://doi.org/ 10.1007/s13351-012-0104-5. 